\title{
Long-term results after surgical treatment of paravalvular leak in the aortic and mitral position
}

\author{
Ismail Bouhout, MD, MSc, ${ }^{\mathrm{a}}$ Amine Mazine, MD, MSc, ${ }^{\mathrm{a}}$ Aly Ghoneim, MD, ${ }^{\mathrm{a}}$ Xavi Millàn, MD, \\ Ismail El-Hamamsy, MD, PhD, ${ }^{a}$ Michel Pellerin, MD, ${ }^{\text {a }}$ Raymond Cartier, MD, \\ Phillipe Demers, MD, MSc, ${ }^{\mathrm{a}}$ Yoan Lamarche, MD, MSc, ${ }^{\mathrm{a}}$ and Denis Bouchard, $\mathrm{MD}, \mathrm{PhD}^{\mathrm{a}}$
}

\begin{abstract}
Objectives: The aim of this study was to determine immediate results and longterm outcomes after surgical management of paravalvular leak (PVL).

Methods: Between 1995 and 2012, a total of 190 patients underwent primary surgical repair $(n=142)$ or valve replacement $(n=48)$ for a PVL at our institution. The PVL was mild in $6(3 \%)$ patients, moderate in $85(45 \%)$, moderate to severe in $84(44 \%)$, and severe in $15(8 \%)$. Among these, $120(63 \%)$ had PVL in the mitral position, 63 (33\%) had PVL in the aortic position, and 7 (4\%) had PVL in both valves. Mean follow-up was $5.3 \pm 4.6$ years.
\end{abstract}

Results: Mean age at surgery was $63 \pm 12$ years $(64 \%$ men). Operative mortality occurred in $13(7 \%)$ patients $(10[8 \%]$ in mitral; $2[3 \%]$ in aortic; and $1[14 \%]$ in double valve procedures). Survival at 1,5 , and 10 years was $85 \% \pm 3 \%$, $73 \% \pm 4 \%$, and $56 \% \pm 5 \%$, respectively. The cumulative incidence of PVL recurrence was $3 \% \pm 1 \%, 14 \% \pm 3 \%$, and $32 \% \pm 6 \%$, at 1,5 , and 10 years, respectively. The number of previous surgeries was a predictor of survival and PVL recurrence. Freedom from New York Heart Association class $\geq$ III was $96 \% \pm 2 \%, 82 \% \pm 4 \%$, and $58 \% \pm 6 \%$, at 1,5 , and 10 years, respectively. The freedom from rehospitalization for heart failure was $92 \% \pm 2 \%$, $83 \% \pm 4 \%$, and $67 \% \pm 6 \%$, at 1,5 , and 10 years.

Conclusions: Surgical treatment of PVL resulted in acceptable outcomes. Nevertheless, the continued risk of PVL recurrence is higher in patients who have had multiple previous surgeries. More studies are needed to compare these results with the transcatheter PVL reduction technique. (J Thorac Cardiovasc Surg 2016;151:1260-6)

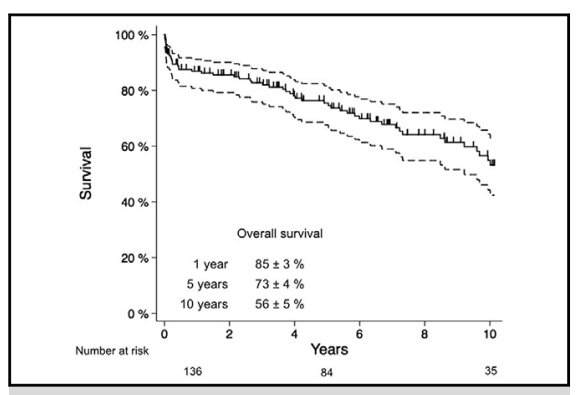

Survival after surgical correction of mitral and/or aortic paravalvular leak.

\section{Central Message}

Surgical correction of PVL is effective in improving patient survival and symptoms.

\section{Perspective}

Paravalvular leak is the most common nonstructural valve replacement dysfunction after heart valve replacement. In the last decade, transcatheter reduction of PVLs has emerged as an alternative to the surgical treatment in inoperable and high-risk patients. However, surgical PVL correction remains the gold standard, as it associated with higher long-term survival and better symptom relief.

See Editorial Commentary page 1267.
A paravalvular leak (PVL) is an incomplete apposition of a heart valve prosthesis on the native valve annulus. This complication is the most common form of nonstructural valve dyfunction observed after a heart valve replacement. ${ }^{1}$ The reported annual incidence of PVL ranges between $0.1 \%$ and $1.0 \%$ per year after aortic valve replacement,

From the ${ }^{\mathrm{a}}$ Division of Cardiac Surgery and ${ }^{\mathrm{b}}$ Department of Interventional Cardiology, Montreal Heart Institute, University of Montreal School of Medicine, Quebec, Canada.

Read at the 2014 AATS Valve Symposium, Istanbul, Turkey, September 4-6, 2014. Received for publication July 23, 2015; revisions received Nov 22, 2015; accepted for publication Nov 28, 2015; available ahead of print Jan 13, 2016.

Address for reprints: Denis Bouchard, MD, PhD, Montreal Heart Institute, University of Montreal School of Medicine, 5000 Bélanger St, Montreal, Quebec H1T 1C8, Canada (E-mail: denis.bouchard@icm-mhi.org).

0022-5223/\$36.00

Copyright $(2) 2016$ by The American Association for Thoracic Surgery

http://dx.doi.org/10.1016/j.jtcvs.2015.11.046 and between $0.2 \%$ and $1.4 \%$ per year after mitral valve replacement. ${ }^{1-4}$

Most patients with mild to moderate PVL remain asymptomatic with no clinical consequence. ${ }^{5}$ However, patients with severe PVL can present with cardiac failure and hemolysis, impairing functional capacity and long-term survival. ${ }^{6}$ Surgical reintervention remains the gold standard therapy for these patients, as it has been reported to improve symptoms and long-term outcomes compared with medical

Scanning this QR code will take you to supplemental figures for this article. 

Abbreviations and Acronyms
CI = confidence interval
HR = hazard ratio
$\mathrm{IQR}=$ interquartile range
NYHA $=$ New York Heart Association
PVL = paravalvular leak
TEE $=$ transesophageal echocardiography

therapy. ${ }^{6}$ Transcatheter reduction of PVLs has emerged as an alternative for patients who are deemed unsuitable for surgery. Recent reports indicate clinical outcomes observed with this technique. ${ }^{7}$ Rigorous data on outcomes after surgical treatment of PVL are thus needed to provide a suitable standard of comparison for these new therapies. The aim of this study was to determine immediate results and long-term outcomes after surgical management of aortic and/or mitral PVL.

\section{METHODS}

\section{Study Population}

Our institution's Heart Valve Clinic database was queried to identify all patients who underwent surgical correction of aortic and/or mitral PVL between January 1995 and December 2012, either as a primary or secondary indication. During this period, 7650 patients underwent valvular heart surgery at our center. Paravalvular leak was defined as a regurgitant jet between prosthesis ring and native tissues on TEE. Patients with active endocarditis at the time of surgery were excluded $(\mathrm{n}=12)$.

The study population comprised a total of 190 patients who underwent either primary surgical repair $(n=142)$ or valve replacement $(n=48)$ for an aortic and/or mitral PVL. Of these, $120(63 \%)$ had PVL in the mitral position, $63(33 \%)$ had PVL in the aortic position, and $7(4 \%)$ had PVL in both valves. A total of $169(89 \%)$ patients had PVL on a mechanical prosthesis.

\section{Data Collection and Outcomes}

Preoperative, operative, and long-term data were prospectively collected through our valve clinic database. All patients were followed on a yearly basis, using mail questionnaires and phone interviews. All postoperative transthoracic echocardiography at follow-up was reviewed to determine the recurrence of PVL. Data were completed and verified by additional data gathered from medical records. Perioperative and longterm outcomes are reported according to Society for Thoracic Surgeons guidelines. ${ }^{8}$

Paravalvular leak location was determined from preoperative transesophageal echocardiography (TEE) and operative TEE $^{9}$ (Figure 1). The primary outcomes were operative mortality $(<30$ days or during index hospitalization) and long-term survival. Secondary outcomes were PVL recurrence, freedom from NYHA functional class $\geq \mathrm{III}$, and freedom from first rehospitalisation for heart failure. The mean and median follow-up were $5.3 \pm 4.6$ years and 5.1 years (interquartile range [IQR]: 2.3-9.0 years), respectively. The completeness of follow-up at 2 years was $72 \%$. The study was approved by the local ethics committee of the Montreal Heart Institute, and a waiver of consent was obtained.

\section{Statistical Analysis}

Continuous data were expressed as mean $+/-$ standard deviation, and categoric variables were presented as frequency (\%). Skewed variables were expressed as median (IQR). Differences between continuous variables were tested using a $t$ test or analysis of variance when normally distributed. Otherwise, a nonparametric test was used. Categoric variables were compared using a Chi-square test or Fisher's exact test, as appropriate.

Actuarial survival and freedom from late adverse events curves were obtained using the Kaplan-Meier method. Survival and late outcomes were compared between groups, by means of the log rank test or Breslow's test, as appropriate. Predictors of long-term survival and recurrence of PVL were assessed using a multivariate Cox regression. All variables deemed to be of clinical significance were considered to have potential to create a confounding effect and were included in the multivariable model building.

Independent variables included in the multivariable Cox regression model for "survival" were: preoperative chronic obstructive pulmonary disease, creatinine clearance $<50 \mathrm{~mL} /$ minute, number of previous cardiac operations (categorized as 1,2 , and $\geq 3$ ), age, pulmonary artery pressure
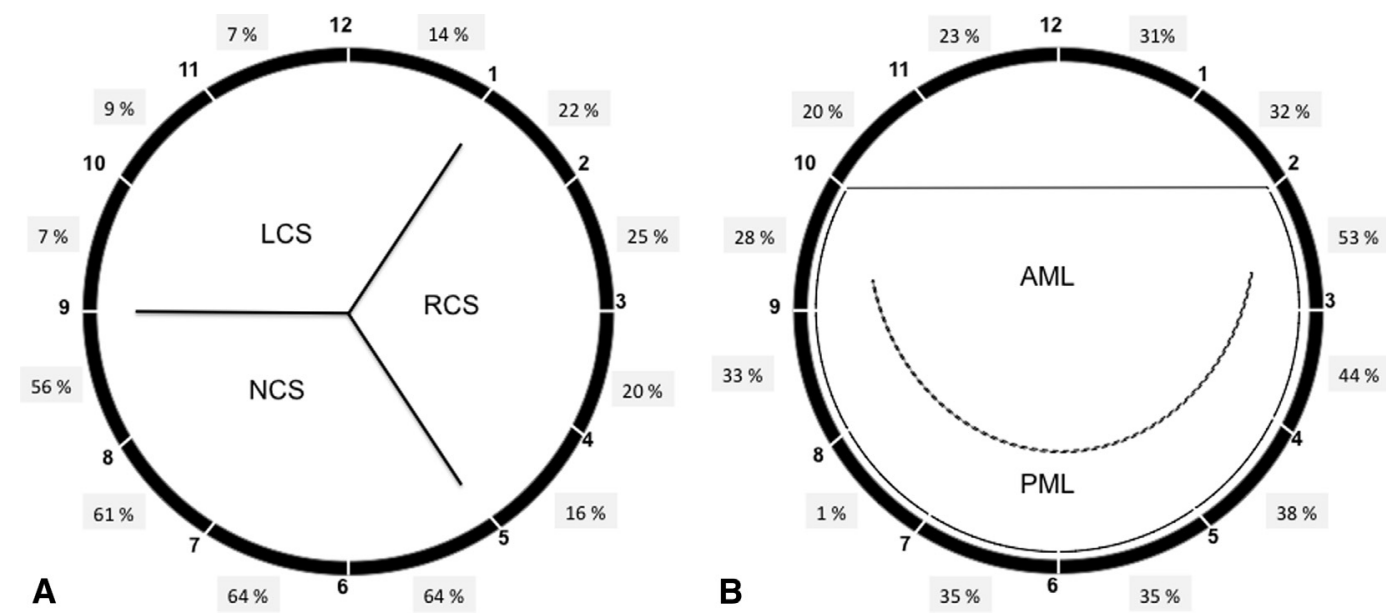

FIGURE 1. A, Aortic and (B) mitral paravalvular leak prevalence in each clock position according to the native valve anatomy. LCS, Left coronary sinus; $R C S$, right coronary sinus; $N C S$, noncoronary sinus; $A M L$, anterior mitral leaflet; $P M L$, posterior mitral leaflet. 
TABLE 1. Demographic characteristics

\begin{tabular}{|c|c|c|c|c|c|}
\hline Variables & Total $(n=190)$ & MVR group $(n=120)$ & $\operatorname{AVR} \operatorname{group}(n=63)$ & DVR group $(n=7)$ & $P$ value \\
\hline Gender, male & $122(64)$ & $65(54)$ & $51(81)$ & $6(86)$ & $<.001$ \\
\hline Age (y) & $63 \pm 12$ & $64 \pm 11 *$ & $61 \pm 12$ & $54 \pm 21^{*}$ & .022 \\
\hline \multicolumn{6}{|l|}{ Comorbidities } \\
\hline Diabetes & $23(12)$ & $12(10) \dagger$ & $10(16) \dagger$ & $1(14)$ & .51 \\
\hline Hypertension & $112(59)$ & $76(63)$ & $31(49)$ & $5(71)$ & .14 \\
\hline Smoker & $22(14)$ & $12(10)$ & $9(14)$ & $1(14)$ & .68 \\
\hline COPD & $35(18)$ & $21(17)$ & $11(17)$ & $3(43)$ & .31 \\
\hline Chronic renal failure & $112(59)$ & $80(67) \dagger$ & $29(46) \dagger$ & $3(43)$ & .02 \\
\hline CAD & $47(25)$ & $29(24)$ & $17(27)$ & $1(14)$ & .55 \\
\hline History of endocarditis & $27(14)$ & $16(13)$ & $8(13)$ & $3(43)$ & .09 \\
\hline Hemolysis & $66(34)$ & $53(44) \dagger$ & $7(11) \dagger, \ddagger$ & $6(85) \ddagger$ & $<.001$ \\
\hline \multicolumn{6}{|l|}{ NYHA } \\
\hline I & $4(2)$ & $1(1)$ & $3(5)$ & $0(0)$ & .10 \\
\hline II & $35(18)$ & $15(12)$ & $17(22)$ & $3(43)$ & \\
\hline III & $129(68)$ & $86(72)$ & $39(62)$ & $4(57)$ & \\
\hline IV & $22(12)$ & $18(15)$ & $4(6)$ & $0(0)$ & \\
\hline \multicolumn{6}{|l|}{ LVEF (\%) } \\
\hline$<40$ & $19(10)$ & $9(8)$ & $8(13)$ & $2(29)$ & .19 \\
\hline $40-55$ & $63(33)$ & 45 (37) & $16(25)$ & $2(29)$ & \\
\hline$>55$ & $108(57)$ & $66(55)$ & $39(62)$ & $3(43)$ & \\
\hline \multicolumn{6}{|l|}{ Prosthesis type } \\
\hline Mechanical & $169(89)$ & $111(93)$ & $52(83)$ & $6(86)$ & .37 \\
\hline Bioprothesis & $21(11)$ & $9(7)$ & $11(17)$ & $1(14)$ & \\
\hline Time since valve replacement (y) & $8.5 \pm 9.8$ & $9.1 \pm 7.8$ & $7.8 \pm 13$ & $4.0 \pm 2.6$ & .41 \\
\hline Primary indication & $171(90)$ & $108(90)$ & $56(89)$ & $7(100)$ & .65 \\
\hline \multicolumn{6}{|l|}{ PVL severity } \\
\hline Mild & $6(3)$ & $3(2)$ & $3(5)$ & $0(0)$ & .70 \\
\hline Moderate & $85(45)$ & $56(47)$ & $26(41)$ & $3(42)$ & \\
\hline Moderate to severe & $84(44)$ & $51(43)$ & $30(48)$ & $3(42)$ & \\
\hline Severe & $15(8)$ & $10(8)$ & $4(6)$ & $1(8)$ & \\
\hline \multicolumn{6}{|l|}{ Number of previous surgeries } \\
\hline 2 & $54(28)$ & $45(38) \dagger$ & $9(14) \dagger$ & $0(0)$ & $<.001$ \\
\hline$\geq 3$ & $35(18)$ & $30(25) \dagger$ & $2(3) \dagger, \ddagger$ & $3(43) \ddagger$ & $<.001$ \\
\hline Euroscore $(\%)$ & $9.0 \pm 7.4$ & $9.6 \pm 6.9$ & $7.9 \pm 8.2$ & $9.7 \pm 6$ & .34 \\
\hline Parsonnet score $(\%)$ & $29 \pm 18$ & $34 \pm 17 \dagger$ & $19 \pm 15 \dagger$ & $23 \pm 15$ & $<.001$ \\
\hline
\end{tabular}

Categoric variables are presented as frequency (\%); continuous variables are presented as mean \pm standard deviation when normally distributed. $M V R$, Mitral valve replacement; $A V R$, aortic valve replacement; $D V R$, double valve replacement; $C O P D$, chronic obstructive pulmonary disease; CAD, coronary artery disease; NYHA, New York Heart Association; $L V E F$, left ventricle ejection fraction; $P V L$, paravalvular leak. *Statistically significant difference between MVR and DVR groups. †Statistically significant difference between MVR and AVR groups. †̦Statistically significant difference between AVR and DVR groups.

$>55 \mathrm{~mm} \mathrm{Hg}$, and a decreased left ventricular ejection fraction $(<50 \%)$. Independent variables included in the multivariable model for "recurrence of PVL" were number of previous cardiac operations, surgical technique (repair vs replacement), and preoperative history of endocarditis. Data were analyzed using SPSS 21.0 (IBM Corp, Armonk, NY) and KaplanMeier curves generated using Stata 13 (Stata Corporation, College Station, Tex)

\section{RESULTS}

\section{Preoperative Baseline Characteristics}

Main preoperative baseline characteristics are presented in Table 1 . The mean age was $63 \pm 12$ years $(64 \%$ men). Median time between valve replacement and surgical correction of PVL was 7 years (IQR: 4-12 years; range: 1 day to 27 years). The period of initial surgery was between 1972 and 2011. The mean Euroscore II ${ }^{10}$ and Parsonnet score ${ }^{11}$ were $9.0 \% \pm 7.4 \%$ and $29 \% \pm 18 \%$, respectively. Hemolysis was present in 66 (34\%) patients and congestive heart failure in $169(89 \%)$ patients. In the aortic position, the PVL was predominantly in the noncoronary commissure, whereas mitral PVLs were predominantly in the postero-median commissure (Figure 1). Fourteen ( $8 \%$ ) patients had a failed transcatheter PVL reduction (residual PVL equal or superior to moderate) attempt prior to surgery.

\section{Operative Details}

Twenty-three $(12 \%)$ patients underwent concomitant coronary artery bypass grafting, and $22(12 \%)$ had other valve procedures. Mitral PVL correction was performed through thoracotomy in $18(15 \%)$ patients. The mean cardiopulmonary bypass and aortic cross-clamp times 
TABLE 2. Operative details and early postoperative complications

\begin{tabular}{|c|c|c|c|c|c|}
\hline Variable & Total $(\mathbf{n}=190)$ & MVR group $(n=120)$ & $\operatorname{AVR}$ group $(n=63)$ & DVR group $(n=7)$ & $P$ value \\
\hline Repair & $142(75)$ & $91(76)$ & $44(70)$ & $7(100)$ & .20 \\
\hline Pericardium or Teflon patch & $5(4)$ & $3(3)$ & $2(5)$ & $0(0)$ & .83 \\
\hline \multicolumn{6}{|l|}{ Concomitant procedures } \\
\hline Isolated PVL surgery & $98(52)$ & $60(50)$ & $33(52)$ & $4(57)$ & .61 \\
\hline Other valve procedure & $55(29)$ & $46(38) *, \dagger$ & $9(14)^{*}$ & $0(0) \dagger$ & $<.001$ \\
\hline CABG & $23(12)$ & $11(9)$ & $11(17)$ & $1(14)$ & .27 \\
\hline Other procedure & $22(12)$ & $12(10)$ & $10(16)$ & $0(0)$ & .31 \\
\hline Bypass time (min) & $121 \pm 59$ & $119 \pm 55$ & $121 \pm 68$ & $146 \pm 55$ & .50 \\
\hline Cross-clamp time (min) & $79 \pm 44$ & $78 \pm 42$ & $77 \pm 47$ & $115 \pm 48$ & .08 \\
\hline Early mortality $(<30 \mathrm{~d})$ & $13(7)$ & $10(8)$ & $2(3)$ & $1(14)$ & .31 \\
\hline Length of stay (d) & $13 \pm 15$ & $15 \pm 17$ & $9.5 \pm 5.5$ & $8 \pm 7$ & .05 \\
\hline Reintervention for bleeding & $15(8)$ & $8(7)$ & $5(8)$ & $2(28)$ & .06 \\
\hline Myocardial infarction & $3(2)$ & $3(3)$ & $0(0)$ & $0(0)$ & .44 \\
\hline Acute renal failure & $31(16)$ & $23(19)$ & $7(11)$ & $1(14)$ & .43 \\
\hline Dialysis & $2(1)$ & $2(2)$ & $0(0)$ & $0(0)$ & .58 \\
\hline $\mathrm{AF}$ & $33(17)$ & $17(14)$ & $15(24)$ & $1(14)$ & .08 \\
\hline PPM & $19(10)$ & $15(13)$ & $4(6)$ & $0(0)$ & .35 \\
\hline Stroke & $4(2)$ & $3(3)$ & $1(2)$ & $0(0)$ & .88 \\
\hline TIA & $3(2)$ & $3(3)$ & $0(0)$ & $0(0)$ & .44 \\
\hline Delirium & $9(5)$ & $4(3)$ & $4(6)$ & $1(14)$ & .22 \\
\hline \multicolumn{6}{|l|}{ Residual PVL at discharge } \\
\hline Trivial to mild & $7(4)$ & $4(3)$ & $3(5)$ & $0(0)$ & .84 \\
\hline Mild to moderate & $2(1)$ & $2(2)$ & $0(0)$ & $0(0)$ & \\
\hline
\end{tabular}

Categoric variables are presented as frequency (\%); continuous variables are presented as mean \pm standard deviation when normally distributed. $M V R$, Mitral valve replacement; $A V R$, aortic valve replacement; $D V R$, double valve replacement; $P V L$, paravalvular leak; $C A B G$, coronary artery bypass grafting; $A F$, atrial fibrillation; $P P M$, permanent pacemaker; TIA, transient ischemic attack. *Statistically significant difference between MVR and AVR groups. †Statistically significant difference between MVR and DVR groups.

were $121 \pm 59$ minutes and $79 \pm 44$ minutes, respectively. Teflon or pericardium patches were used in $5(4 \%)$ patients. Postoperative TEE showed trivial-to-mild residual PVL in $7(4 \%)$ patients, and mild-to-moderate residual PVL in 2 (1\%) patients. No severe residual PVL occurred (Table 2).

\section{Early Complications}

Overall, 30-day mortality was $7 \%(n=13 ; 3 \%[n=2]$ for aortic valve replacement; $8 \%[\mathrm{n}=10]$ for mitral valve replacement; and $14 \%[\mathrm{n}=1]$ for double valve replacement). The ratio between observed early mortality over expected, by Euroscore II, was 0.76 ( $95 \%$ confidence interval $[\mathrm{CI}]=0.41-1.24$; Fisher's exact test: $P=.865)$. Reintervention for bleeding occurred in $15(8 \%)$ patients. Acute renal failure was reported in $31(16 \%)$ patients, $2(6 \%)$ of which required dialysis. Postoperative stroke and transient ischemic attack occurred in $4(2 \%)$ and $3(2 \%)$ patients, respectively. The median hospital stay was 10 days [IQR: 7-15 days]. Postoperative complications are summarized in Table 2.

\section{Long-Term Outcomes}

The cumulative survival was $85 \% \pm 3 \%, 73 \% \pm 4 \%$, and $56 \% \pm 5 \%$, at 1,5 , and 10 years (Figure 2, A). No survival difference was found between the aortic versus mitral valve replacement groups (Figure 2,B). The cause of death was cardiac in $18(29 \%)$ patients, valve related in $2(3 \%)$, noncardiac in $10(16 \%)$, and unknown in $32(51 \%)$.

In multivariable Cox regression, preoperative chronic obstructive pulmonary disease (hazard ratio $[\mathrm{HR}]=4.31$, $95 \%$ CI $=2.89-8.12, P<.001)$; creatinine clearance $<50 \mathrm{~mL} /$ minute $(\mathrm{HR}=2.25,95 \% \mathrm{CI}=1.18-4.29$, $P=.013)$, a history of $\geq 3$ previous cardiac operations $(\geq 3$ vs $1[\mathrm{HR}=3.20,95 \% \mathrm{CI}=1.55-6.59, P=.002]$ and $\geq 3$ vs $2[\mathrm{HR}=2.02,95 \% \mathrm{CI}=1.1-4.13, P=.043])$ and older age $(\mathrm{HR}=1.04,95 \% \mathrm{CI}=1.01-1.07$, $P=.005)$ were predictors of long-term mortality. No difference was found in survival between patients who underwent surgery between 1995 and 2003, versus between 2004 and $2012(71 \% \pm 3 \%$ and $71 \% \pm 7 \%$ at 5 years, respectively; log-rank: $P=.52)$.

The cumulative incidence of PVL recurrence was $3 \% \pm 1 \%, 14 \% \pm 3 \%$, and $32 \% \pm 6 \%$ at 1,5 , and 10 years, respectively (Figure E1). The mean time between PVL correction and recurrence was $5.9 \pm 4.1$ years. The freedom from PVL recurrence $\geq 1$ was $99 \% \pm 1 \%$, $92 \% \pm 2 \%$, and $70 \% \pm 6 \%$, at 1,5 , and 10 years, respectively. No difference was observed in PVL recurrence rate between the surgical repair and replacement groups (Figure E2). Closing the PVL with pericardium or a Teflon patch was not associated with lower PVL recurrence (Fisher's exact test: $P=.25$ ). 


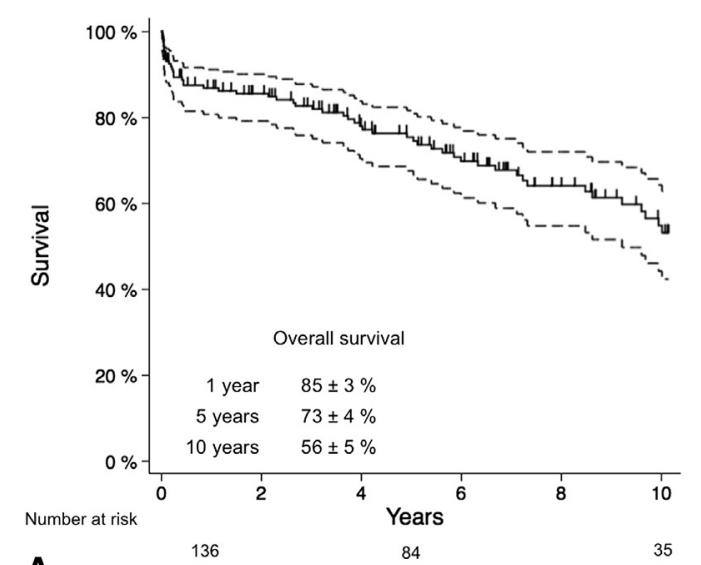

A

136

84

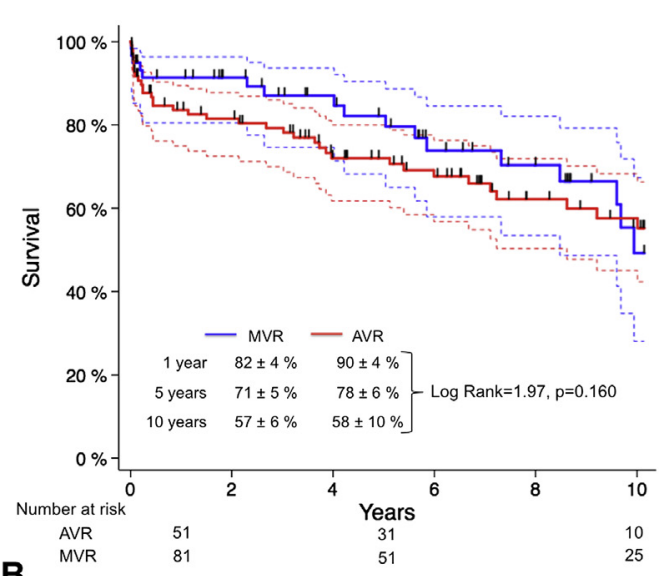

FIGURE 2. A, Cumulative survival after surgical treatement of paravalvular leak. B, Cumulative survival in the mitral valve replacement and aortic valve replacement groups. Dashed lines show $95 \%$ confidence intervals. $M V R$, Mitral valve replacement; $A V R$, aortic valve replacement.

In multivariable Cox regression, a history of $\geq 3$ previous cardiac operations was associated with an increased risk of PVL recurrence compared with first redo procedures $(\mathrm{HR}=1.58,95 \% \mathrm{CI}=1.07-2.45, P=.02)$. Prior PVL location was not a predictor of PVL recurrence. The freedom from surgical reintervention for PVL was $98 \% \pm 1 \%$, $94 \% \pm 2 \%$, and $82 \% \pm 5 \%$, at 1,5 , and 10 years, respectively. Patients underwent reintervention for PVL at a median time of 7.1 years (IQR: 2.4-12.0 years). The freedom from transcatheter PVL reduction was $99 \% \pm 1 \%$ and $94 \% \pm 3 \%$, at 5 and 10 years, respectively. Patients underwent transcatheter PVL reduction at a median time of 5.8 years (IQR: 3.3-7.0 years). The freedom from functional class NYHA $\geq$ III was $96 \% \pm 2 \%, 82 \% \pm 4 \%$, and $58 \% \pm 6 \%$ at 1,5 , and 10 years, respectively (Figure 3 ).

The freedom from $\geq 1$ hospitalization for heart failure was $92 \% \pm 2 \%, 83 \% \pm 4 \%$, and $67 \% \pm 6 \%$, at 1,5 ,

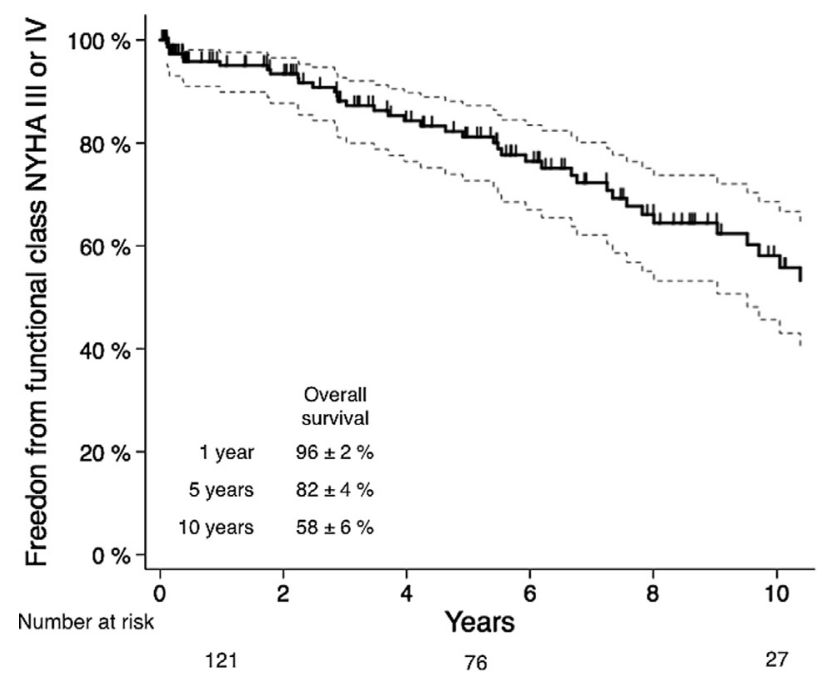

FIGURE 3. Freedom from NYHA functional class III or IV. Dashed lines show $95 \%$ confidence intervals. NYHA, New York Heart Association. and 10 years (Figure E3). No difference was found in the freedom from PVL recurrence, the freedom from NYHA functional class $\geq$ III, or the freedom from first hospitalization for heart failure between patients who underwent surgery between 1995 and 2003 compared with between 2004 and 2012 (log-rank: $P=.08, P=.44$ and $P=.39$, respectively).

\section{DISCUSSION}

Paravalvular leak (PVL) is the most frequent cause of nonvalvular dysfunction and has major implications on long-term survival after heart valve surgery. ${ }^{6,12}$ Recent evidence $^{13}$ showed increased mortality in patients with moderate, versus no or mild, PVL after transcatheter AVR. An increase in mortality was observed as early as 1 month after the procedure. ${ }^{14}$ Paravalvular leak is the first cause of reintervention in patients undergoing mechanical valve replacement. ${ }^{15}$ Surgical correction remains the treatement of choice, as it has been shown to reduce long-term mortality compared with conservative treatment. ${ }^{6}$ Few studies have reported long-term outcomes after surgical PVL correction in the modern era. ${ }^{6,16-18}$ The present study is one of the largest series, with longest follow-up.

Aortic PVL was predominantly seen in the noncoronary sinus and mitral PVL in the postero-median commissure. This finding is in accordance with studies from De Cicco and colleagues ${ }^{18,19}$ on anatomic location of PVL in $>160$ patients. The authors suggested that these findings could result from anatomic weakness and vulnerability to mechanical stress of the membranous septum and the posterior mitral annulus.

Several factors have been associated with the development of PVL. A friable annulus (calcification, infection, connective tissue disease) is one of the most important risk factors of early PVL, as sutures can be pulled out during knot tying. ${ }^{3}$ In addition, continuous sutures have been 
associated with a higher incidence of early $\mathrm{PVL}^{20}$ and should be avoided. In the present study, all initial valve replacements were done using interrupted sutures. On the other hand, late PVL is most often secondary to prosthetic endocarditis or incomplete debridement of a calcified annulus. ${ }^{21}$ This finding highlights the importance of a proper annulus decalcification for preventing PVL.

Mechanical prostheses predominated in the present cohort $(89 \%)$ ). In contrast, Akins and colleagues ${ }^{16}$ reported 136 consecutive patients undergoing PVL correction; 50\% had a bioprosthesis. This discrepancy is due to a preference for mechanical prosthesis implantation in our institution. No perioperative residual PVL was found in $95 \%$ of patients in this cohort, which highlights the fact that surgical PVL treatment is a highly effective procedure.

Early mortality reported in this study was relatively low considering the high-risk patient population, including $46 \%$ who had undergone $>2$ previous cardiac surgeries. The early death in the aortic group $(3 \%)$ was lower than in previous reports ${ }^{6,16-18}$ where mortality ranged from $4.5 \%$ to $7.1 \%$. Akins and colleagues ${ }^{16}$ reported mortality comparable to that in our serie after mitral correction of PVL $(7.6 \%)$. In a recent report from Taramasso and colleagues, ${ }^{17}$ early mortality was higher in patients undergoing mitral PVL correction $(13 \%)$. The trend toward higher early mortality in the mitral group, compared with the aortic group, is in accordance with previous studies on redo mitral valve surgery. ${ }^{16-18,22}$ Additionaly, a high incidence of postoperative acute kidney injury occurred $(16 \%)$. This finding may be explained by the high prevalence of preoperative chronic kidney disease, multiple previous cardiac operations, and congestive heart failure in the study cohort, all of which are associated with an increased risk of postoperative acute kidney injury. ${ }^{23}$

Long-term mortality reported in the present study was high ( $4.4 \%$ per patient-year), given that the mean age at surgery was 63 years, but this percentage does not differ from previous reports on results after redo cardiac surgery. ${ }^{24,25}$ This increased mortality may be partially explained by the greater prevalence of disease in the patient population, as the preoperative creatinine clearance and the number of previous cardiac surgeries were predictors of long-term mortality. In addition, more than half of determined longterm deaths were cardiac and thus could be due to the long-term impact of PVL recurrence on left ventricular remodeling.

A substantial number of PVL recurrences were seen during follow-up ( $4 \%$ per patient-year). The only predictor of PVL recurrence was the number of previous cardiac operations. Similar results were reported in a study by Akins and colleagues ${ }^{16}$ in which the mean number of reoperations in patients with recurrent PVL was 5. This finding raises the hypothesis that PVL recurrence is mainly the result of an annulus disease, rather than surgical issues. No difference was observed between patients who underwent surgery before versus after 2004 .

Similarly, no difference was seen between repairs and replacements. Strategies aimed at mitigating this high rate of recurrence should be explored. We hypothesize that in patients undergoing valve replacement for PVL correction, selection of a prosthesis with a larger stent could produce a better seal on the diseased annulus. Furthermore, we recommend that a greater number of sutures be used both in patients undergoing PVL repair and those undergoing a valve replacement.

Transcatheter PVL reduction recently emerged as an alternative to conventional surgery in high-risk or nonoperable patients. A recently published meta-analysis has shown that this procedure has the potential for relative improvement in cardiac mortality and symptoms when successful. Although surgical treatment of PVL remains the gold standard, more comparative studies are needed to assess which patients could benefit from transcatheter PVL correction.

\section{Limitations}

This study is a retrospective observational single-center study. The cause of death was unknown in the majority of patients, which hampers determination of any conclusion on the role of cardiac deaths in the high mortality rate observed. Despite a good mean follow-up, the completeness of follow-up at 2 years was $72 \%$. As the PVL incidence was not monitored in the initial cohort of patients who underwent surgery between 1972 and 1995, the total PVL recurrence and reintervention rates could not be determined in the present study. Only those patients who underwent reintervention for PVL between 1995 and 2011 could be identified.

\section{CONCLUSIONS}

Life expectancy and symptom relief after surgical correction of PVL were acceptable. Hazard of recurrence remains high despite low residual PVL at discharge, suggesting that PVL is more a disease of the annulus than a surgical issue.

\section{Conflict of Interest Statement}

P.D. and D.B. have received proctorship fees from Sorin Canada. All other authors have nothing to disclose with regard to commercial support.

\section{References}

1. Hammermeister K, Sethi GK, Henderson WG, Grover FL, Oprian C, Rahimtoola SH. Outcomes 15 years after valve replacement with a mechanical versus a bioprosthetic valve: final report of the Veterans Affairs randomized trial. J Am Coll Cardiol. 2000;36:1152-8.

2. Davila-Roman VG, Waggoner AD, Kennard ED, Holubkov R, Jamieson WR, Englberger L, et al. Prevalence and severity of paravalvular regurgitation in the Artificial Valve Endocarditis Reduction Trial (AVERT) echocardiography study. J Am Coll Cardiol. 2004;44:1467-72. 
3. Rallidis LS, Moyssakis IE, Ikonomidis I, Nihoyannopoulos P. Natural history of early aortic paraprosthetic regurgitation: a five-year follow-up. Am Heart J. 1999;138:351-7.

4. Duncan BF, McCarthy PM, Kruse J, Andrei A-C, Li Z, Russell HM, et al. Paravalvular regurgitation after conventional aortic and mitral valve replacement: a benchmark for alternative approaches. J Thorac Cardiovasc Surg. 2015;150: 860-8.e1.

5. Garcia E, Sandoval J, Unzue L, Hernandez-Antolin R, Almeria C, Macaya C. Paravalvular leaks: mechanisms, diagnosis and management. EuroIntervention. 2012;8(Suppl Q):Q41-52.

6. Genoni M, Franzen D, Vogt P, Seifert B, Jenni R, Kunzli A, et al. Paravalvular leakage after mitral valve replacement: improved long-term survival with aggressive surgery? Eur J Cardiothorac Surg. 2000;17:14-9.

7. Millan X, Skaf S, Joseph L, Ruiz C, Garcia E, Smolka G, et al. Transcatheter reduction of paravalvular leaks: a systematic review and meta-analysis. Can J Cardiol. 2015;31:260-9.

8. Akins CW, Miller DC, Turina MI, Kouchoukos NT, Blackstone EH, Grunkemeier GL, et al. Guidelines for reporting mortality and morbidity after cardiac valve interventions. Ann Thorac Surg. 2008;85:1490-5.

9. Mahjoub H, Noble S, Ibrahim R, Potvin J, O’Meara E, Dore A, et al. Description and assessment of a common reference method for fluoroscopic and transesophageal echocardiographic localization and guidance of mitral periprosthetic transcatheter leak reduction. JACC Cardiovasc Interv. 2011;4:107-14.

10. Nashef SA, Roques F, Sharples LD, Nilsson J, Smith C, Goldstone AR, et al. EuroSCORE II. Eur J Cardiothorac Surg. 2012;41:734-44; discussion 734-44.

11. Parsonnet V, Dean D, Bernstein AD. A method of uniform stratification of risk for evaluating the results of surgery in acquired adult heart disease. Circulation. 1989;79:I3-12.

12. Taramasso M, Maisano F, Denti P, Guidotti A, Sticchi A, Pozzoli A, et al. Surgical treatment of paravalvular leak: long-term results in a single-center experience (up to 14 years). J Thorac Cardiovasc Surg. 2015;149:1270-5.

13. Mack MJ, Leon MB, Smith CR, Miller DC, Moses JW, Tuzcu EM, et al. 5-year outcomes of transcatheter aortic valve replacement or surgical aortic valve replacement for high surgical risk patients with aortic stenosis (PARTNER 1): a randomised controlled trial. Lancet. 2015;385: 2477-84.

14. Kodali SK, Williams MR, Smith CR, Svensson LG, Webb JG, Makkar RR, et al Two-year outcomes after transcatheter or surgical aortic-valve replacement. $N$ Engl J Med. 2012;366:1686-95.
15. Bouhout I, Stevens LM, Mazine A, Poirier N, Cartier R, Demers P, et al. Longterm outcomes after elective isolated mechanical aortic valve replacement in young adults. J Thorac Cardiovasc Surg. 2014;148:1341-6.e1.

16. Akins CW, Bitondo JM, Hilgenberg AD, Vlahakes GJ, Madsen JC, MacGillivray TE. Early and late results of the surgical correction of cardiac prosthetic paravalvular leaks. J Heart Valve Dis. 2005;14:792-9; discussion 799-800.

17. Taramasso M, Maisano F, Latib A, Denti P, Guidotti A, Sticchi A, et al. Conventional surgery and transcatheter closure via surgical transapical approach for paravalvular leak repair in high-risk patients: results from a single-centre experience. Eur Heart J Cardiovasc Imaging. 2014;15:1161-7.

18. De Cicco G, Lorusso R, Colli A, Nicolini F, Fragnito C, Grimaldi T, et al. Aortic valve periprosthetic leakage: anatomic observations and surgical results. Ann Thorac Surg. 2005;79:1480-5.

19. De Cicco G, Russo C, Moreo A, Beghi C, Fucci C, Gerometta P, et al. Mitral valve periprosthetic leakage: anatomical observations in 135 patients from a multicentre study. Eur J Cardiothorac Surg. 2006;30:887-91.

20. Dhasmana JP, Blackstone EH, Kirklin JW, Kouchoukos NT. Factors associated with periprosthetic leakage following primary mitral valve replacement: with special consideration of the suture technique. Ann Thorac Surg. 1983;35:170-8.

21. Kliger C, Eiros R, Isasti G, Einhorn B, Jelnin V, Cohen H, et al. Review of surgical prosthetic paravalvular leaks: diagnosis and catheter-based closure. Eur Heart J. 2013;34:638-49.

22. Castillo-Sang M, Guthrie TJ, Moon MR, Lawton JS, Maniar HS, Damiano RJ Jr, et al. Outcomes of repeat mitral valve surgery in patients with pulmonary hypertension. Innovations (Phila). 2015;10:120-4.

23. Kristovic D, Horvatic I, Husedzinovic I, Sutlic Z, Rudez I, Baric D, et al. Cardiac surgery-associated acute kidney injury: risk factors analysis and comparison of prediction models. Interact Cardiovasc Thorac Surg. 2015;21:366-73.

24. Garrido-Olivares L, Maganti M, Armstrong S, David TE. Clinical outcomes of aortic root replacement after previous aortic root replacement. J Thorac Cardiovasc Surg. 2013;146:611-5.

25. Fukunaga N, Okada Y, Konishi Y, Murashita T, Koyama T. Does the number of redo mitral valve replacements for structural valve deterioration affect early and late outcomes?: Experience from 114 reoperative cases. J Heart Valve Dis. 2014; 23:688-94.

Key Words: paravalvular leak, aortic valve, mitral valve, heart valve replacement, redo surgery 


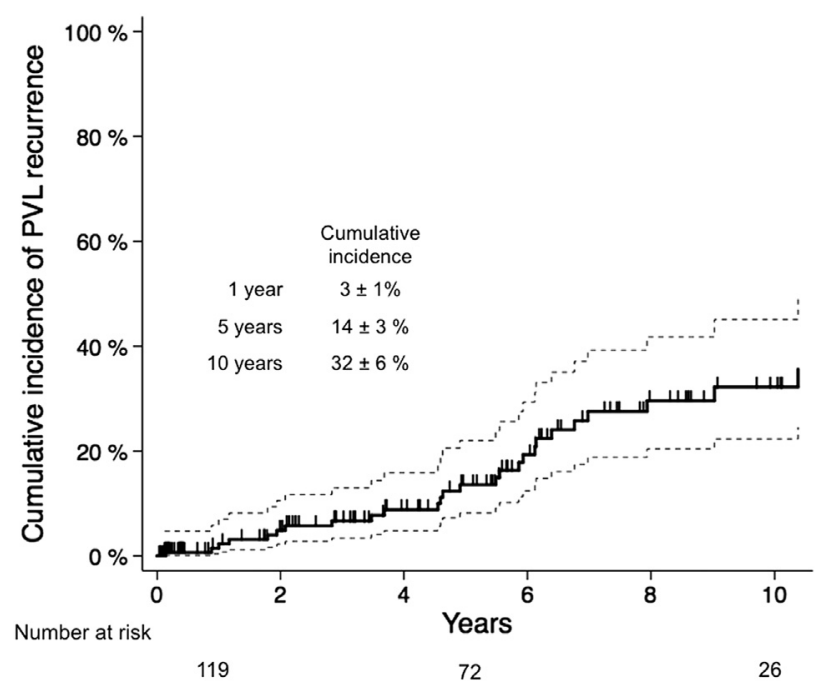

FIGURE E1. Cumulative incidence of paravalvular leak recurrence. Dashed lines show $95 \%$ confidence intervals. $P V L$, Paravalvular leak.

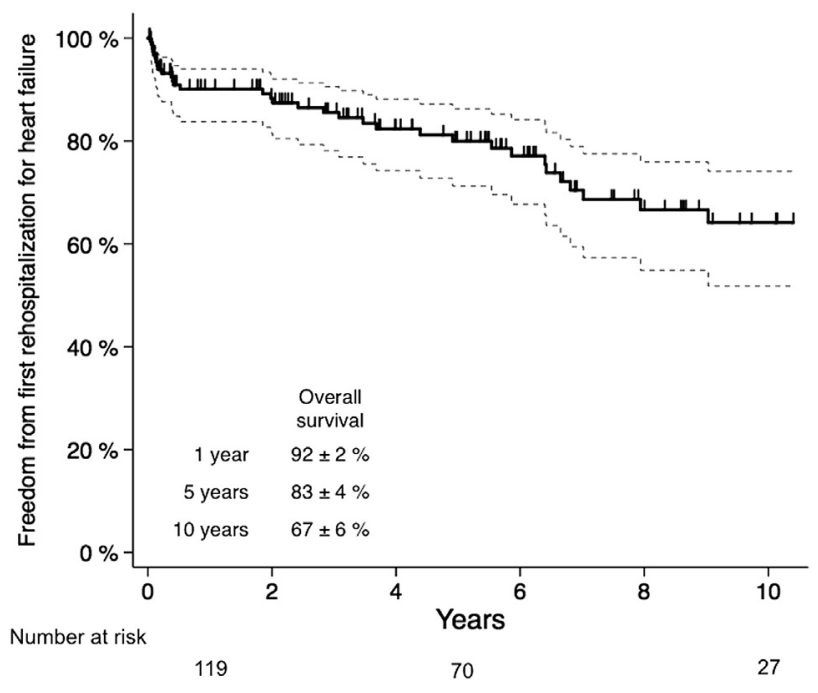

FIGURE E3. Freedom from first rehospitalization for heart failure. Dashed lines show $95 \%$ confidence intervals.

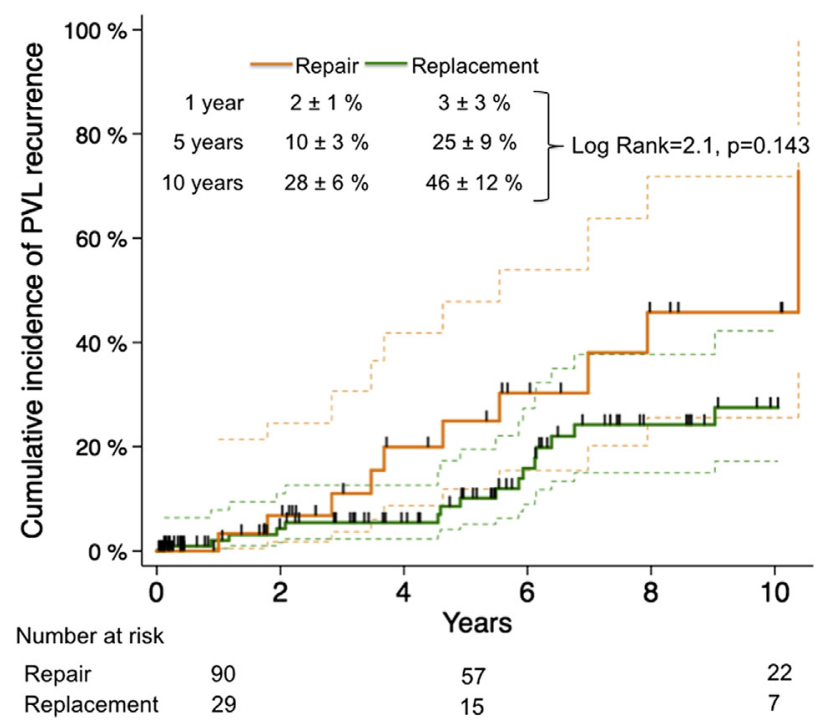

FIGURE E2. Cumulative incidence of paralvalvular leak recurrence in the mitral and aortic valve replacement groups. Dashed lines show $95 \%$ confidence intervals. $P V L$, Paravalvular leak. 